\title{
A crise internacional: reflexões e discussões
}

Adolfo Sachsida*

RESUMO - Este artigo relata minha visão sobre os principais determinantes da crise financeira atual. $\mathrm{O}$ artigo também expõe argumentos contra a atual maneira que os governos têm intervido no mercado, ressaltando a participação original do governo (e não dos mercados) em gerar a crise. Questões como a estatização do sistema financeiro e a ajuda a empresas com dificuldade também são discutidas.

Palavras-chave: Crise financeira. Intervenção do governo. Conjuntura econômica.

\section{REFLEXÕES SOBRE A CRISE I: A CRISE ATUAL E A CRISE DE 1929}

Muitos analistas tentam encontrar semelhanças entre a crise financeira atual e a crise de 1929. A rigor existe apenas uma grande semelhança entre a crise atual e a de 1929: ambas foram causadas pelo Estado.

Em 1929 os Estados Unidos adotavam o padrão-ouro. Com seguidos déficits em sua balança comercial, os americanos tinham que transferir ouro para outros países. Com menos reservas em ouro, eram obrigados então a reduzir a quantidade de dólares na economia. Isso levou a uma brutal queda na liquidez da economia americana. Foi nesse ponto que surgiu o Banco Central americano (FED). O FED foi criado justamente para evitar problemas de liquidez, mas ao invés de aumentar a liquidez do sistema optou por reduzi-la. Foi esse o começo da RECESSÃO americana. A DEPRESSÃO americana só começou com o segundo movimento errado do governo: restrições ao comércio internacional (com a ideia de melhorar a situação das empresas americanas) e maior poder de barganha aos sindicatos (com a ideia de melhorar a situação dos trabalhadores). As políticas públicas americanas, destinadas a aliviar os efeitos da crise, tiveram o efeito contrário e transformaram uma crise passageira numa depressão profunda. Até hoje algumas pessoas acreditam que a economia americana só se recuperou por causa da segunda guerra mundial. Elas estão certas em parte, não porque a economia americana precisa da guerra (como argumentam), mas sim porque foi durante a guerra que as políticas públicas adotadas ao longo da década de 30 foram abandonadas. Somente após abandonar idéias erradas é que a economia americana se recuperou.

\footnotetext{
* Doutor em Economia pela Universidade de Brasília. Professor da Universidade Católica de Brasília e pesquisador do IPEA. Endereço eletrônico: sachsida@hotmail.com. Sítio na internet: www.bdadolfo.blogspot.com.
} 
Atualmente os Estados Unidos adotam o câmbio flexível (diferente do padrão-ouro de 1929). Essa é uma diferença importante, pois agora déficits comerciais (ao contrário de 1929) não são capazes de afetar severamente a liquidez da economia. Mas tal qual em 1929, o governo americano está transformando uma crise passageira numa depressão severa. As medidas de apoio ao setor financeiro logo se alastrarão para outros setores da economia. Restrições ao comércio internacional logo serão adotadas e compensações serão estendidas aos trabalhadores. O resultado disso será similar ao de 1929: o governo terá gerado mais outra brutal recessão.

O que gerou a depressão econômica de 1929 não foi a crise no setor bancário americano, foi sim a sequência de más políticas públicas adotadas pelo governo na década de 1930. As políticas públicas americanas transformaram uma crise passageira numa depressão severa. Essa é outra semelhança entre a crise atual e a crise de 1930: em ambas o Estado primeiro causou a crise; e depois a título de salvar a economia transformou a crise numa depressão.

\section{REFLEXÕES SOBRE A CRISE II: A ESTATIZAÇÃO DOS BANCOS}

Poucas ideias são tão ruins que não podem ser pioradas. $O$ recente apoio estatal ao setor financeiro ao redor do mundo é um exemplo claro. Note como ideias originalmente ruins foram se transformando aos poucos em verdadeiros pesadelos do absurdo. Tão logo a crise atingiu Wall Street o Banco Central americano (FED) anunciou que aumentaria a liquidez da economia. Era um pacote de míseros bilhões de dólares, mas mesmo assim já havia me posicionado contra esse pacote. $O$ argumento era simples: a ajuda beneficiava bancos que haviam agido de maneira muito arriscada no passado. Os bancos entenderam o recado do FED e ao invés de realizarem os ajustes necessários passaram a cobrar mais recursos do governo. O tempo passou e o governo americano anunciou um pacote de US\$ 300 bilhões ao setor financeiro. Após isso nova ajuda foi anunciada, agora de US\$ 700 bilhões. Na semana seguinte o pacote já somava US\$ 850 bilhões. Mas nada, repito, até o momento absolutamente nada parece superar o suprassumo dos absurdos que foi anunciado nessa semana: estatizar bancos. O que será que nos aguarda na próxima semana?

Estatizar bancos significa usar dinheiro dos contribuintes para a compra de um ativo que NÃO É função do governo prover. Se o governo pode estatizar bancos o que o impedirá de estatizar supermercados? Por que não estatizar também parte das montadoras de veículos? A lista é infindável, mas vamos voltar à questão de se estatizar bancos. Quando é que o 
governo irá devolver o controle dos bancos ao mercado? Bancos com participação do governo receberão algum tipo de vantagem adicional? Mas a principal pergunta é: se o governo é dono do banco e a função do governo é maximizar o bem estar da sociedade, então a função do banco não será mais maximizar lucros. Ou seja, como evitar que os bancos assumam funções que prejudiquem sua rentabilidade e tragam ainda mais risco para o sistema financeiro? Aliás, foi justamente a participação de dois bancos (Fanny May e Freddy Mac) com fortes ligações com o Estado um dos pilares da atual crise no sistema financeiro.

Sou contrário a qualquer tipo de ajuda a bancos. Contudo, se for para capitalizar os bancos a sugestão mais viável é outra: ao invés do governo assumir parte do controle dos bancos, por que não obrigar que outros bancos (ou fundos) assumam o controle dos bancos em dificuldade? Claro que isso envolve um grau enorme de arbitrariedade, mas estatizar bancos envolve um grau ainda maior de arbitrariedade. Contudo, ao obrigar que um banco assuma o controle de outro o governo estaria obrigando um ajuste DENTRO do sistema financeiro, e não empurrando o ajuste para toda a sociedade. Outro detalhe, é razoável assumir que outros bancos sejam melhores gestores de bancos que o governo. A operacionalização dessa idéia é mais simples do que parece: nenhum pacote é necessário, basta ao governo OBRIGAR que alguns bancos (ou fundos) aceitem descontos em suas dívidas (isentando parte da dívida e trocando outra parte da dívida por ações do banco em dificuldade). No caso americano isso implica em mudança de lei e requer aprovação do Congresso, mas aí vem a parte boa: esse expediente JÁ foi usado com sucesso no passado.

Estatizar bancos é um grande erro, os falecidos bancos estaduais brasileiros são um exemplo de quão ruim essa idéia pode ser. Mas como disse antes: poucas idéias são tão ruins que não podem ser pioradas.

\section{REFLEXÕES SOBRE A CRISE III: O EFEITO MANADA E A IRRACIONALIDADE DOS MERCADOS}

Temos ouvido muito os analistas reclamarem da irracionalidade dos mercados. Afirmam eles que o sobe e desce nas bolsas de valores não é racional, mas sim resultado de um efeito de manada. Isto é, basta um grande investidor começar a vender (ou comprar) que todos os demais o seguem. Tal comportamento gera enorme instabilidade nas bolsas de valores.

Na minha modesta opinião quem é louco rasga dinheiro, se não rasga dinheiro então é porque não é louco. Até o momento não vi ninguém rasgar dinheiro, sendo assim não posso concordar que falte racionalidade ao mercado. Aliás, o único que eu vi rasgar dinheiro até o 
momento é o governo, então este sim pode ser o louco. Mas acreditar que alguém que comanda um fundo de um bilhão de dólares é louco não me parece razoável.

O sobe e desce das bolsas de valores tem outra explicação muito mais razoável: especulação aliada à necessidade de se saldar posições previamente assumidas. Acontece que muitas empresas sofreram prejuízos razoáveis na bolsa americana. Com isso elas precisam vender suas posições em outras partes do mundo para saldarem suas dívidas. Quando um número grande de empresas vende suas posições é natural que o preço das ações caia. Sabendo que várias empresas precisam saldar suas posições num curto espaço de tempo, o especulador faz uso dessa informação para lucrar mais. Grandes especuladores apenas se retiram do mercado por um período curto de tempo para forçar a queda de preço das ações, quando estas caem eles entram comprando. Note que tal comportamento replica muito bem o sobe e desce atual das bolsas de valores.

Um detalhe importante e que não pode passar despercebido é o papel fundamental assumido pelo Estado para AGRAVAR essa situação. Se as empresas tivessem CERTEZA de que o governo não iria intervir no mercado, elas iriam vender suas posições aos poucos (justamente para evitar a pressão dos especuladores). Vendendo suas posições aos poucos as empresas não evitariam prejuízos, mas evitariam o desespero de ter que vender tudo de última hora. Isso geraria uma queda suave no mercado de ações. Pelo lado do especulador, este saberia que caso se ausentasse do mercado não teria muito a ganhar. Afinal, as empresas agora podem esperar mais e não estão mais esperando até o último minuto para vender suas posições. CONTUDO, quando o governo sinaliza que irá intervir na economia, várias empresas param de vender suas posições. Elas agora aguardam até o último momento na esperança de receber ajuda do governo. Quando a ajuda do governo não aparece tais empresas são obrigadas a agir de última hora e temos então as grandes quedas da bolsa. Quedas essas que se transformam em grandes altas nos dias seguintes, quando os especuladores tomam vantagem de sua posição.

Em resumo, basta o governo parar de ajudar, ou de tentar ajudar, as empresas ineficientes que rapidamente esse sobe e desce das bolsas desaparecerá. É a perspectiva da ajuda governamental, e não o efeito manada, a responsável pela instabilidade atual dos mercados. Isto é, o mercado NADA TEM DE IRRACIONAL. Irracional é a atitude do governo. 


\section{GREENSPAN E A CRISE FINANCEIRA AMERICANA}

Em 1997 Peter Ireland publicou um importante artigo mostrando que as autoridades monetárias americanas não tinham conseguido derrotar a inflação. Para Ireland a baixa inflação americana era muito mais consequência da boa sorte (choques positivos na economia) do que do bom manejo da política monetária. Em 2006, eu e mais dois colegas fizemos algumas extensões no modelo de Ireland e chegamos aos mesmos resultados. Para ser mais explícito, nosso artigo mostrava que nada havia de genial na política monetária adotada pelo badalado Alan Greenspan, então presidente do Banco Central Americano (FED).

Em 2007 explodiu a crise no mercado sub-prime americano e absolutamente ninguém se importou em checar a culpa de Alan Greenspan. Por que Greenspan é tão badalado? Uma inspeção no período em que Greenspan chefiava o FED nos mostra que ele SEMPRE procurou acomodar os choques na economia. Qualquer pessoa com formação mais forte em economia monetária sabe que está é a PIOR postura possível. Com seu comportamento Alan Greenspan incentivou o mercado a apostar sempre no perfil acomodador do FED e, consequentemente, se expor a riscos cada vez maiores. Greenspan tinha horror a recessões, e procurou evitá-las ao máximo. Um dos artifícios para evitar recessões era manter a taxa de juros extremamente baixa. Contudo, essa postura estimulou um incrível aumento na demanda por crédito e o excesso de crédito, em última instância, foi o causador da crise no mercado sub-prime americano. Tivesse Greenspan permitido algumas pequenas, e esporádicas, recessões dificilmente teríamos a crise financeira atual que está se abatendo sobre a economia americana.

Resumindo: foi o FED, por meio de seu presidente Alan Greenspan, que insistiu numa política de juros extremamente baixa, o principal causador da crise financeira atual nos Estados Unidos. Mais uma vez vemos a contribuição perversa do Estado para transformar pequenos e temporários desajustes em sérias crises financeiras. Mas o problema não termina aqui. Tal como venho alertando em meu blog desde o ano passado: a maneira que o FED está se portando na crise atual está ERRADA. Ajudar bancos falidos só aumenta o custo do ajuste. Ajudar financeiras que fizeram escolhas erradas só ESTIMULA que outras financeiras cometam o mesmo erro no futuro.

O que o FED deveria fazer é simples: NADA. A política atual do FED, de tentar amenizar a crise, é semelhante a adotada por Greenspan e terá o mesmo resultado: irá gerar uma crise maior ainda no futuro. Ben Bernanke (atual presidente do FED) sabe disso, mas ele 
confia que será capaz de AUMENTAR a regulação do mercado financeiro para evitar novas crises. Pois eu tenho uma dica para Bernanke: quem ganha 100 mil por ano geralmente não é mais esperto do quem ganha 10 milhões por ano. Os reguladores do FED ganham 100 mil/ano. Os especuladores de Wall Street ganham 10 milhões/ano. Cedo ou tarde Wall Street vai achar um jeito de burlar as regulações e uma nova crise, mais profunda que a atual, aparecerá no horizonte.

\section{A CRISE FINANCEIRA E O EFEITO CONTÁGIO}

Quando um banco vai à falência seus clientes perdem parte do dinheiro aplicado naquele banco. As empresas com aplicações naquele banco ficam sem recursos para pagarem seus funcionários e seus fornecedores. Sem receber da empresa os funcionários também não conseguem pagar suas dívidas e a crise vai se alastrando por toda a economia. Esse efeito é conhecido por "efeito contágio". Efeito contágio é o fato de que empresas saudáveis podem ser prejudicadas por problemas originados fora de sua esfera de decisão.

O efeito contágio é o argumento usado pelos defensores da ajuda estatal aos bancos, e financeiras, em dificuldade nos Estados Unidos. Para tais pessoas, caso o governo americano não ajude os bancos teremos um contágio do setor financeiro para o resto da economia. Isso levaria a uma quebradeira generalizada entre as empresas e a uma grande recessão.

Tenho uma pergunta: por que ajudar apenas os bancos? O efeito contágio não se refere apenas a bancos, refere-se sim a qualquer empresa suficientemente grande. Por exemplo, se o Wall Mart estivesse em dificuldade o argumento referente ao "efeito contágio" também poderia ser invocado para ajudar essa grande empresa. Afinal, se o Wall Mart quebrar todos seus funcionários perderão seus empregos (e o Wall Mart tem mais funcionários do que o exército americano). Sem emprego os funcionários não terão como pagar suas dívidas e a crise no Wall Mart irá se espalhar por toda a economia. Mais do que isso, indo à falência o Wall Mart não poderia pagar seus fornecedores, e estes não poderiam pagar seus funcionários e mais uma vez a crise se espalharia por toda a economia. Outro detalhe, o Wall Mart também tem um setor financeiro. Assim, não existe grande diferença entre o Wall Mart e um banco.

O "efeito contágio" é apenas um argumento desenvolvido por grandes empresas para justificar seus pedidos de ajuda governamental; e é a maneira como o governo justifica gastar dinheiro do contribuinte para ajudar empresas privadas. Aceitar o "efeito contágio" como argumento para ajudar empresas significa dar carta branca às grandes companhias, significa que o contribuinte terá sempre que arcar com as más decisões dos grandes conglomerados. 
Numa economia de mercado existem períodos de prosperidade e de crise. Manda o bom senso que as companhias usem os períodos de prosperidade para se prepararem para os períodos de crise. Mas hoje parece que as empresas, cientes do apoio do governo, gastam na bonança para receberem socorro dos contribuintes nas adversidades.

O mercado financeiro não é diferente de nenhum outro mercado. As mesmas regulamentações que se aplicam ao mercado de bananas devem ser aplicadas ao mercado financeiro. As mesmas regras que valem para os produtores rurais devem também valer para os especuladores financeiros. Novas empresas vão e vêm na economia, os bancos não são exceção e não devem ter tratamento diferenciado.

\section{A CRISE FINANCEIRA E A ATUAÇÃO DO BANCO CENTRAL BRASILEIRO}

A economia brasileira tem sofrido relativamente pouco com a crise financeira internacional. Ao contrário do que afirma o Ministro Mantega isso não se deve a nossas reservas de 200 bilhões de dólares. Esse montante pode parecer alto, mas em momentos de ataques especulativos esse volume desaparece em uma semana. $\mathrm{O}$ que realmente tem evitado maiores turbulências na economia brasileira é que agora, ao contrário de 1999, a taxa de câmbio é flexível. Apesar de ter recebido pouco crédito por sua importância, o mecanismo do câmbio flutuante proporciona três grandes vantagens: a) evita ataques especulativos contra a moeda doméstica; b) amortece os choques externos; e c) faz com que a volatilidade da bolsa de valores nacional seja menor. Isso ocorre pois quando um investidor precisa cobrir perdas em outro local do mundo, ele primeiro retira dinheiro dos países com câmbio fixo (assim ele evita perder dinheiro com a desvalorização cambial).

A ÚNICA maneira de a crise financeira internacional atingir seriamente o Brasil é se o governo brasileiro tentar fixar a taxa de câmbio. Enquanto mantivermos a taxa de câmbio flexível nosso país passará relativamente bem por esse momento de turbulência. Claro que existem outras maneiras da crise internacional afetar o Brasil, mas, enquanto a taxa de câmbio permanecer flexível, esses efeitos serão passageiros e de pouca magnitude. De maneira geral são cinco os canais de transmissão da crise para dentro da economia brasileira: a) restrições de crédito; b) falta de liquidez; c) queda nas exportações; d) erro de gerenciamento cometido por algumas empresas; e e) queda na riqueza das famílias decorrente das perdas no mercado acionário.

O item "c" acima, devido ao mecanismo de câmbio flexível, deverá ser bem menos severo do que a maioria acredita. Quanto ao item "d" não cabe ao governo intervir, se uma 
empresa quis se arriscar em operações financeiras sofisticadas nada mais justo do que ela pagar por isso. Quanto ao item "e" devemos lembrar que nos últimos quatro anos os investidores em bolsa tiveram um lucro formidável, assim é natural que possam arcar com algum prejuízo sem grandes transtornos. Além disso, com o passar do tempo espera-se que essa perda seja bem menor. O que realmente preocupa são os itens "a" e "b" acima, não por causa de sua severidade econômica, mas sim porque é ali que políticas econômicas administradas pelo Estado podem transformar uma crise passageira num pesadelo de grandes proporções.

Para melhorar a liquidez do sistema basta o Banco Central brasileiro (BC) diminuir o compulsório que os bancos são obrigados a manter. Para diminuir o problema de crédito externo cabe ao $\mathrm{BC}$ vender dólares no mercado à vista (para que empresas possam saldar seus compromissos no exterior, mas não com o objetivo de segurar o preço do dólar). Essas foram, acertadamente, as primeiras medidas que o BC tomou. Contudo, o BC está extrapolando suas funções e realizando operações que não são de sua alçada. Não cabe ao BC realizar operações de swap cambial, essas operações envolvem não só riscos, mas sobretudo sinalizam para uma intervenção no mercado cambial. Na última semana o BC vem realizando operações que podem configurar que ele está tentando fixar a taxa de câmbio. Está é a única coisa que não podemos fazer. Outra operação estranha é a recente medida provisória que autoriza o BC a comprar carteiras de crédito de bancos em dificuldade. A explicação é que o Banco Central irá trocar reservas cambiais por títulos de primeira qualidade. Contudo: 1) Se os títulos são de primeira qualidade, então por que o BC precisa intervir? 2) Qual será o preço pago nesses títulos? 3) Quem define quais títulos são de primeira linha? As agências de rating? 4) Qual o montante que será gasto nessa operação? 5) Além dos títulos, quais outras garantias que o BC irá receber? (suspeito que nenhuma).

Mas até o momento a notícia que mais assusta é a frase do presidente Lula que "ameaça tomar de volta o dinheiro liberado para os bancos que não estiverem repassando os recursos". Em palavras, o Presidente da República está pressionando os bancos para que estes realizem empréstimos. Os bancos não estão realizando empréstimos pois estão sendo cautelosos, não querem se arriscar em empréstimos que se revelem de difícil solvência no futuro, e os bancos estão certos nisso. Errado está o presidente em insistir nesse ponto. Não custa lembrar que boa parte da crise financeira atual foi causada por política similar adotada pelo governo americano: foi a ingerência governamental em dois grandes fundos (Fanny May e Freddy Mac), pressionando-os a realizarem empréstimos imobiliários arriscados, o maior 
motivador dos problemas que o mundo enfrenta hoje. Parece que Lula quer repetir no Brasil o erro cometido pelo governo americano.

\section{O QUE VEM DEPOIS DOS US\$ 700 BILHÕES?}

Os analistas financeiros falam com propriedade que a ajuda federal ao setor financeiro americano será inferior a U\$ 700 bilhões. Afinal, os títulos podres que seriam comprados pelo governo têm algum valor, ou seja, 700 bilhões de dólares é o custo máximo para o contribuinte. Alguns dos analistas dizem até que o governo pode lucrar com os títulos podres... Claro, claro, em teoria quase tudo é possível. Mas se os títulos podres são tão bom negócio assim, então por que o setor privado não os compra?

Os analistas financeiros estão ERRADOS: 700 bilhões é apenas o começo. O Senado americano já aprovou um projeto MODIFICADO; ou seja, aprovou um projeto que AUMENTA as garantias para quem tem depósitos em banco. Essa medida, apesar de não ter custo imediato, AUMENTA o ônus do Tesouro Americano no caso de quebra de alguns bancos. Quando se manda um pacote de ajuda para o Congresso você sabe o que mandou, mas não sabe o que vai sair.

O custo do pacote de ajuda ao setor financeiro não termina no Congresso: vários indivíduos irão pressionar para terem perdão em suas dívidas de cartão de crédito ou em suas hipotecas imobiliárias. Várias empresas irão ao Congresso com o chapéu na mão: Ford e GM são as empresas fora do setor financeiro que já foram pedir ajuda ao governo federal. Todas elas com argumentos similares aos usados pelo setor financeiro: uma crise no setor automobilístico teria graves consequências para a economia. Ano que vem teremos: Boeing, American Airlines, Continental e Delta recebendo ajuda do governo. Afinal, uma crise no setor aéreo tem efeitos gravíssimos sobre toda a economia. No final de 2009 será a vez de ajudar as siderúrgicas americanas. Afinal, siderurgia é um setor estratégico. Enfim, a conta não para de crescer. Ou melhor, para no dia que acabarem os recursos do já combalido Tesouro Americano. Nesse dia, o governo fará o que deveria ter feito hoje: não cabe ao setor público salvar da falência empresas privadas.

Os 700 bilhões de dólares do pacote de ajuda ao setor financeiro americano é apenas a ponta do iceberg. Assim que o governo aprovar esse pacote o próprio setor financeiro começará a dizer que 700 bilhões é pouco para evitar a crise, e mais dinheiro deverá ser DADO aos bancos para o bem da economia. Pior do que isso: o pacote de ajuda quebra uma 
regra básica do capitalismo: investidores que aceitam correr riscos em busca de lucro devem também ser responsáveis em caso de prejuízos.

\section{GASTO PÚBLICO EM INFRAESTRUTURA}

Várias vozes têm se manifestado em favor do aumento dos gastos públicos em infraestrutura. Para eles uma melhora na infraestrutura pode aumentar a produtividade total da economia e impulsionar o crescimento econômico. Por exemplo, uma melhora na qualidade das estradas pode facilitar o transporte de cargas e baratear o custo de transporte. Dessa maneira, se o governo aumentasse seus gastos com a manutenção de estradas estaria também estimulando a economia.

Infelizmente, em economia, as coisas nunca são tão simples. Devemos lembrar que o aumento dos gastos públicos, mesmo que em infraestrutura, implica numa redução do montante de recursos disponíveis ao setor privado. Isto é, menos dinheiro para as pessoas e para as empresas. Alguns irão argumentar que o gasto público em infraestrutura tem um efeito dinâmico, ou seja, irá aumentar a quantidade de recursos futuros disponíveis na economia. Infelizmente as coisas não são tão simples assim. Afinal, sempre poderemos argumentar que o setor privado poderia realizar os mesmos gastos, mas de maneira mais eficiente. Pior, não basta ao setor público ser tão eficiente quanto o setor privado, ele necessita ser mais eficiente. O motivo é simples: o gasto do governo é financiado, cedo ou tarde, por impostos. $\mathrm{E}$ os impostos afetam negativamente a produtividade de toda a economia. Assim, aumentar os gastos do governo implica que, cedo ou tarde, os impostos terão que aumentar, e isso prejudica a eficiência de toda a sociedade. Dessa maneira, o investimento do governo precisa ser mais eficiente que o investimento privado (para compensar a perda de eficiência gerada pelo aumento dos impostos). Alguém acredita que a eficiência do governo seja tão alta?

Existe ainda outro sério problema relacionado ao gasto público em infraestrutura. Quem garante que o governo está investindo no local correto? Quando o governo melhora a infraestrutura de determinado local, ele está artificialmente tornando tal localidade mais atrativa ao investimento privado. Ou seja, está tornando viáveis investimentos que antes não seriam realizados. Este custo implica que sempre que o governo cortar tais subsídios (pois este é o nome do investimento público) ele estará condenando todos os investimentos que em tais localidades foram feitos. Com isso, fica evidente que aquele gasto original do governo nunca será transitório. Pior, os subsídios para aquela região irão sempre aumentar com o 
argumento de proteger o desenvolvimento da região. Querem um exemplo disso? Olhem para Manaus.

Eu desconfio muito de investimentos públicos em infraestrutura: se eles fossem tão bons o próprio setor privado já os teria realizado. Se o governo é necessário é porque existe alguma coisa mal explicada. Com o tempo, o investimento público em infraestrutura torna viáveis regiões (e indústrias) que de outro modo nunca teriam prosperado. O custo de se manter tais regiões (e indústrias) aumenta com o tempo, colocando em risco todo o bem estar da sociedade. Se é para o governo gastar, fico com a sugestão de Homer Simpson: que o governo mande o Tesouro pagar cerveja pra todo mundo. No dia seguinte o máximo que teremos é uma ressaca.

\section{A ECONOMIA PELO LADO DA DEMANDA}

O Presidente Lula e vários de seus Ministros de Estado vêm afirmando que em 2009 o Brasil se transformará num canteiro de obras. Essa é a idéia do Plano de Aceleração do Crescimento (PAC) proposto pelo governo federal. O PAC já foi inclusive rotulado de "vacina" contra a crise. O PAC usará recursos públicos para financiar investimentos pelo país. Segundo os técnicos do governo, o aumento dos gastos públicos aumentará a demanda agregada da economia. Com o aumento da demanda os empresários poderiam contratar mais funcionários e teriam mais ânimo para investir. Assim teríamos um aumento tanto no consumo (propiciado pelo aumento no nível de empregos) como no investimento agregado. Em resumo, a economia cresceria motivada pelo aumento nos gastos públicos. Discordo dessa idéia por pelo menos três motivos.

Primeiro, gastos públicos, investimento e consumo são todos componentes da curva de demanda agregada da economia. A idéia do governo é que esse aumento da demanda leve a um aumento da oferta. Mas no curto prazo pode ocorrer que apenas os preços aumentem (aumento da inflação). E no longo prazo, nada garante que o governo tenha gasto recursos nos locais mais adequados.

Segundo, os recursos são sempre finitos. Se o governo demanda mais recursos para gastar, ele precisa retirar esses recursos de algum lugar. Se o governo gasta muito, sobram poucos recursos para o setor privado se utilizar. Ou seja, o setor público e o setor privado competem por recursos. Quando o setor público aumenta seu tamanho, no curto prazo, invariavelmente sobra menos espaço para o setor privado. Novamente, o mais provável é que esse aumento dos gastos públicos conduza a um aumento no nível de preços. 
Terceiro, a aposta do governo refere-se ao longo prazo. $O$ governo aposta que o aumento dos gastos públicos em obras de infraestrutura irá estimular o aumento do investimento privado no longo prazo. Com uma melhor infra-estrutura a economia poderia crescer a taxas mais altas. O problema desse argumento é que ele assume que o governo sabe exatamente onde deve investir. E que, além disso, ele é capaz de realizar tais investimentos de maneira mais eficiente que o setor privado. Creio que a evidência histórica demonstra que o governo prefere investimentos grandiosos (e visíveis) a investimentos eficientes.

Nos Estados Unidos, temos a economia pelo lado da oferta (corte de impostos para estimular trabalho e investimento privado). No Brasil, temos a economia pelo lado da demanda (motivada por aumento do tamanho do Estado). Na Alemanha nazista, a ideia de ter um Estado forte controlando o investimento privado funcionou muito bem. Em menos de oito anos os nazistas tiraram a Alemanha de um estado de caos para se tornar uma potência mundial. O problema é o que veio depois... O problema é que uma vez criado um monstro é impossível controlá-lo. Como vocês podem notar, minha objeção à economia pelo lado da demanda não é apenas econômica. É também moral.

\section{LIÇÕES DE 1930 PARA A CRISE AMERICANA ATUAL}

Após a Grande Depressão americana de 1930, vários estudiosos tentaram descobrir as origens daquela catástrofe econômica. Pensadores como Milton Friedman atribuíram boa parte da responsabilidade ao comportamento desastroso do Banco Central americano (FED). Em 1930 a taxa de câmbio seguia o padrão-ouro, isto é, era fixa. Assim, superávits ou déficits comerciais tinham o poder de alterar a oferta de moeda. Para Friedman, durante o ano de 1929, o movimento da Balança Comercial americana retirou muita moeda da economia, gerando dificuldade de liquidez no setor financeiro. Essa falta de liquidez teria sido a origem da Grande Depressão. Para Friedman o FED poderia ter amenizado a depressão caso aumentasse a liquidez do sistema. Contudo, em 1929, o FED fez justamente o contrário agravando a depressão.

O FED esta usando as lições de 1930 para resolver a crise atual, ou seja, esta aumentando a liquidez do sistema financeiro para evitar falências generalizadas. Contudo, existe uma grande diferença entre 1930 e 2008: a taxa de câmbio agora é flexível. Isto é, a origem da crise não está na brutal redução da oferta de moeda em decorrência de déficits no Balanço de Pagamentos (como ocorreu em 1929), mas sim num comportamento de aceitação de risco por parte de várias empresas. Dessa maneira, AUMENTAR a oferta de moeda é a 
resposta ERRADA para a crise atual. E o FED, tal como no passado, está PIORANDO a economia ao invés de melhorá-la. VOLTO A REPETIR: esse comportamento do FED será usado para justificar mais intervenção governamental no futuro. E mais intervenção do governo, geralmente, é o prelúdio de crises mais severas.

Por fim, quero saber quanto a CHINA PERDEU com a crise americana. Não tenho dúvidas de que cedo ou tarde esses dados virão à tona, e ficará comprovado que o governo chinês foi QUEM MAIS PERDEU DINHEIRO com a crise americana. Afinal, grande parte dos superávits comerciais chineses estavam aplicados no mercado americano. 
